\title{
TRABALHO E PRECARIZAÇÃO SOCIAL
}

\author{
INTRODUÇÃO
}

\author{
Graça Druck \\ Tânia Franco **
}

As transformações do trabalho inscritas no marco da globalização neoliberal e da reestruturação produtiva ${ }^{1}$ nas últimas décadas podem ser sintetizadas nos processos de flexibilização, desregulamentação e precarização social. Diversos estudos e pesquisas $^{2}$ têm evidenciado a consolidação da flexiprecarização e o seu caráter multidimensional - compreendendo as dimensões econômica, política, social, cultural - que se realiza nos planos macro, microssocial e do indivíduo (intra e interpsíquico), ${ }^{3}$ assumindo configurações específicas de

* Doutora em Ciências Sociais, com pós-doutorado na Universidade de Paris XIII. Professora associada I do Departamento de Sociologia e da Pós-Graduação em Ciências Sociais da Universidade Federal da Bahia - PPGCS/ FFCH/UFBA. Pesquisadora do Centro de Recursos Humanos/FFCH/UFBA e do CNPq

Faculdade de Filosofia e Ciências Humanas. Estrada de São Lázaro, 197. Federação, Cep: 40.210-730. Salvador, Bahia - Brasil.druckg@gmail.com

* * Doutora em Ciências Sociais pela Universidade Federal da Bahia. Pesquisadora do Centro de Recursos Humanos/FFCH/UFBA. franctania@gmail.com

${ }^{1}$ Numa perspectiva crítica em relação ao processo de globalização ver Chesnais (1996), Bourdieu (1998, 2001); Harvey (2004), Passet (2002).

${ }^{2}$ Castel (1998, 2009); Harvey (1992, 2004); Bourdieu (1997, 1998, 2001); Appay,Thébaud-Mony (1997); Hirata, Préteceille (2002); Linhart (2007); Sennett (2006, 1999); Antunes (2000); Antunes, Braga (2009); Druck, Franco (2007); Franco, Druck, Seligmann-Silva (2010), dentre outros.

${ }^{3}$ Apesar de não contemplados neste dossiê, vale ressaltar a importância e o intenso desenvolvimento dos estudos etnia, gênero, geracionais e de novas inter-relações entre família e indivíduo, ${ }^{4}$ redefinindo as relações sociais e o tecido social. Trata-se de um processo mundial, com traços e características que perpassam invariavelmente as diversas configurações do mundo do trabalho, apresentando, entretanto, nuances e especificidades nacionais, regionais e setoriais.

Nesse amplo espectro de estudos sobre a precarização social, inscreve-se este número especial do Caderno $C R H$, que focaliza um tema central da sociologia contemporânea - trabalho e precarização social -, trazendo à tona desafios e questões cruciais tanto para a academia, estrito senso, quanto para os diversos agentes de transformação social. Reúne contribuições de autores (as) que se debruçaram sobre a questão dos fundamentos teóricos e (ou) sobre as diversidades, as nuances e as evidências empíricas do processo de precarização do trabalho, trazendo para o campo

no campo da Saúde Mental Relacionada ao Trabalho/ SMRT. Ver, dentre outros, Dejours $(2007,2004,1999)$; Seligmann-Silva $(2011,2004,2001,1994)$; Heloani, Barreto (2010); Thébaud-Mony, Robatel (2009), Glina, Rocha (2010).

${ }^{4}$ Hirata (2002); Hirata, Guimarães, Sugita (2008); Segnini (2008), dentre outros. 
da reflexão elementos gerais e teóricos, bem como outros específicos e singulares.

Este dossiê temático congrega autores (as) que se reuniram no Seminário "Trabalho, Precarização Social e Resistências", nos dias 19 e 20 de novembro de 2009, realizado pelo Centro de Recursos Humanos (CRH) e o Programa de PósGraduação em Ciências Sociais (PPGCS), ambos da Faculdade de Filosofia e Ciências Humanas da Universidade Federal da Bahia, em parceria com a Fundacentro/Ba. Nele, foram debatidas pesquisas e atuações no campo da precarização social do trabalho, trazendo para o âmbito da reflexão formulações teóricas, diferentes expressões da precarização, repercussões para a saúde do trabalhador - especialmente as LER/Dort (Lesões por Esforços Repetitivos/Distúrbios Osteomusculares Relacionados ao Trabalho) - e experiências que significaram avanços nas formas de resistência reveladas pela atuação do poder público.

O seminário reuniu pesquisadores de instituições estrangeiras, nacionais e do estado da Bahia com os quais o CRH/FFCH/UFBA mantém intercâmbio e cooperações de longa data, através de pesquisas que refletem várias interfaces no campo do trabalho contemporâneo. Voltado para um público variado de estudantes, professores, pesquisadores, profissionais e técnicos de empresas públicas e privadas, sindicalistas, lideranças de movimentos sociais, membros do poder público e do Estado, o evento buscou difundir conhecimento científico crítico e nutrir o debate na sociedade, favorecendo a sensibilização, a atualização e a formação de agentes sociais voltados para questões contemporâneas cruciais.

O seminário e este dossiê representam o êxito de uma perspectiva solidária, ao tempo em que constituem um fruto do diálogo e da interdisciplinaridade na produção do conhecimento sobre a realidade social, contribuindo para potencializar as redes de interlocução e cooperação. Vale ressaltar, ademais, que os artigos deste dossiê foram escritos especificamente para integrarem este número especial, de forma a aprofundar os temas tratados no seminário.

O dossiê reflete convergências ao longo do tempo, que favorecem o avanço do conhecimento científico complexo, com resultados teóricos e empíricos que permitem uma compreensão tanto das tendências gerais quanto dos matizes enriquecedores de linhas de tempo e de nuances internacionais, nacionais e locais. Além das contribuições teóricas, congrega autores que combinam pesquisa - produção de conhecimento - com extensão universitária e (ou) atuações diretas e indiretas em instituições públicas voltadas para a regulação social na perspectiva da defesa dos direitos civis e dos trabalhadores, ou seja, numa perspectiva de análise crítica e de resistência à precarização.

Tendo como eixo temático a precarização social e do trabalho, a estrutura do dossiê transita entre os fundamentos da teoria marxista sobre o trabalho, as concepções e perspectivas críticas sobre a precarização social, suas novas características e repercussões sociais, reconfigurações familiares e aspectos da saúde dos trabalhadores - especialmente as LER/Dort.

Os artigos trazem contribuições em vários campos entrelaçados pelo processo de precarização do trabalho. A teoria sociológica crítica é revisitada eatualizada ao serem focalizados fenômenos contemporâneos. Conceitos clássicos sobre o trabalho e suas nuances, concepções sobre precarização social e do trabalho, diagnósticos e evidências empíricas de precarização do trabalho-ameaças aos direitos sociais, do trabalho e da saúde - e das formas de resistência são contemplados em análises que perpassam as dimensões micro e macrossociais.

No primeiro artigo, Helena Hirata apresenta um estudo comparativo entre França, Japão e Brasil no contexto atual de crise, em que, a partir de Robert Castel, delineia novas tendências da precarização quanto à divisão sexual do trabalho precário e às repercussões sobre a saúde física e mental dos trabalhadores.

Annie Thébaud-Mony, percorrendo linhas de tempo, apresenta as conquistas históricas dos trabalhadores na França e como o processo de precarização atinge, de forma multidimensional, os direitos sociais, destacando as dimensões do 
trabalho, do emprego e do direito à saúde, explicitando o caso emblemático do câncer profissional na região parisiense e o surgimento de redes sociais de resistência.

Voltada para o diagnóstico da precarização social no Brasil, como fenômeno novo e velho, diferente e igual, de caráter macro e microssocial, Graça Druck contextualiza o quadro do trabalho na América Latina, com base nos estudos da Organização Internacional do Trabalho (OIT) - seus novos e velhos desafios - e apresenta indicadores quantitativos e qualitativos de precarização do trabalho e de resistências no país.

Rodrigo Carelli, no atual contexto de crise do Direito do Trabalho e da regulação social pelo Estado, analisa o papel fundamental exercido pelo Ministério Público do Trabalho no Brasil como depositário e defensor dos direitos humanos e do trabalho, no enfrentamento do processo de precarização social.

Liliana Segnini revisita a teoria sociológica após o século XIX, ressaltando múltiplas faces do trabalho precário e da vulnerabilidade, especialmente das mulheres trabalhadoras, referenciais a partir dos quais identifica novos aspectos e permanências em sua análise recente sobre a precariedade e vulnerabilidade de trabalhadores altamente qualificados do mundo artístico no Brasil contemporâneo. Evidencia como o Estado tem sido um dos principais agentes nesse processo de desmonte dos direitos sociais.

Iracema Guimarães aborda questões teóricas e metodológicas, apresentando evidências empíricas de territórios de precariedade e de mudanças na relação família-comunidade, em bairros periféricos de Salvador (BA), no contexto da desregulamentação do trabalho e perda de direitos sociais que têm levado trabalhadores a uma maior dependência das políticas assistenciais.

Denise Lemos aborda as transformações do trabalho docente nas Universidades Federais, em especial na Universidade Federal da Bahia, nos marcos do processo de precarização e da alienação do trabalho. Evidencia a perda de autonomia do docente, submetido a um sistema de exigências e de controle do trabalho, em contradição com a ca- pacidade física e psíquica humana.

Ricardo Antunes discute a problemática da alienação e (ou) estranhamento a partir das concepções de Marx, na empresa capitalista moderna, delineando seus principais traços e diferenciações ao longo do tempo. Avança com uma fenomenologia da subjetividade, fundamentada em Lukács, destacando a importância das noções de reificações inocentes e reificações estranhadas para a compreensão dessa dimensão no capitalismo contemporâneo.

Discutindo as repercussões da precarização do trabalho no campo específico da saúde do trabalhador, Paulo Pena aborda a questão das Lesões por Esforços Repetitivos (LER) em operadores de telemarketing em Salvador (BA), submetidos ao taylorismo cibernético. Problematiza as novas estratégias gerenciais, discute a criação de "hipercorpos" nas relações entre operadores e clientes, destacando sua importância para a compreensão da questão da subjetividade no trabalho, dos estigmas e de particularidades na produção e prevenção das LER.

Rita Fernandes traz uma perspectiva importante no campo da saúde do trabalhador, ao abordar, por um lado, a dor musculoesquelética em trabalhadores como expressão do desequilíbrio entre as capacidades humanas e as modalidades de organização do trabalho. Por outro, ao focalizar o sofrimento e o adoecimento de trabalhadores da indústria de plásticos da Região Metropolitana de Salvador (RMS, BA), realiza um diálogo inovador entre pesquisa epidemiológica e Análise Ergonômica do Trabalho (AET).

Por fim, com a lente dos conceitos de alienação do trabalho (Marx) e de habitus (Bourdieu), Tânia Franco percorre a linha do tempo das sociedades capitalistas urbano-industriais, destacando rupturas e continuidades no mundo do trabalho e suas repercussões na saúde dos trabalhadores e no meio ambiente. As atuais crises, social e ambiental, têm raízes comuns e profundas no seio dessas sociedades, sendo a expressão contemporânea de um longo e contínuo processo histórico de despertencimento social e de desenraizamento humano em relação à natureza. 
Agradecemos aos autores e autoras pela imensa generosidade e disponibilidade, muitas vezes em circunstâncias francamente adversas, ao tempo em que expressamos a nossa firme perspectiva de solidariedade e continuidade de interlocução e cooperação.

Agradecemos à FUNDACENTRO - Bahia/ MTE e ao CNPq, apoiadores do Seminário TrabaIho, Precarização Social e Resistências. Agradecemos à Fapesb que, através do Edital 002/2010 de Apoio à Publicação Científica e Tecnológica, viabilizou a publicação deste número especial do Caderno CRH.

Agradecemos a receptividade, dedicação e ricas sugestões do corpo de pareceristas, o que permitiu aprimorar cada artigo deste dossiê, bem como o cuidadoso trabalho da Editoria da revista.

(Recebido para publicação em 20 junho de 2011) (Aceito em 03 agosto de 2011)

\section{REFERÊNCIAS}

ANTUNES, R. Os sentidos do trabalho: ensaio sobre a afirmação e a negação do trabalho. 2.ed. São Paulo: Boitempo, 2000.

; BRAGA, R. Infoproletários - degradação real do trabalho virtual. São Paulo: Boitempo, 2009.

APPAY, B.; THÉBAUD-MONY, A. Précarisation sociale, travail et santé. Paris: IRESCO, 1997.

BOURDIEU, P. (Org.) A miséria do mundo. 2.ed. Petrópolis: Vozes, 1997.

Contrafogos: táticas para enfrentar a invasão neoliberal. Rio de Janeiro: Jorge Zahar Ed., 1998.

Contrafogos 2: por um movimento social europeu. Rio de Janeiro: Jorge Zahar Ed., 2001.

CASTEL, R. As metamorfoses da questão social: uma crônica do salário. Rio de Janeiro: Vozes, 1998. Seuil, 2009.

La montée des incertitudes. Paris: Édtions du

Les gagnants du changement et les autres. Problèmes politiques et sociaux. La Documentation Française, Paris, n.965, p.21-24, out., 2009.

CHESNAIS, F. A mundialização do capital. São Paulo: Xamã, 1996.

DEJOURS, C. A banalização da injustiça social. Rio de Janeiro: Fundação Getúlio Vargas, 1999.

Activisme professionnel: masochisme, compulsivité ou alienation? Travailler, Paris, v.1, n.11, p.25-40, 2004.
. Conjurer la violence-travail, violence et santé. Paris: Payot, 2007.

DRUCK, G; FRANCO, T. A perda da razão social do trabalho: terceirização e precarização do trabalho. São Paulo: Boitempo, 2007.

FRANCO, T.; DRUCK, G.; SELIGMANN-SILVA, E. As novas relações de trabalho, o desgaste mental do trabalhador e os transtornos mentais no trabalho precarizado. Revista Brasileira de Saúde Ocupacional, São Paulo, v.35, n. 122, p. 229-248, 2010.

GLINA, D. M. R.; ROCHA, L. E. Saúde mental no trabaIho: da teoria à prática. São Paulo: Roca, 2010.

HARVEY, D. Condição pós-moderna. São Paulo: Ed. Loyola, 1992.

2004.

O novo imperialismo. São Paulo: Ed. Loyola,

HELOANI, R.; BARRETO, M. Aspectos do trabalho relacionados à saúde mental: assédio moral e violência psicológica. In: GLINA, D. M. R.; ROCHA, L. E. Saúde mental no trabaIho: da teoria à prática. São Paulo: Roca, 2010. p.31-48.

HIRATA, H. Nova divisão sexual do trabalho? Um olhar voltado para a empresa e a sociedade. São Paulo: Boitempo Editorial, 2002.

; PRETÉCEILLE, E. Trabalho, exclusão e precarização socioeconômica: o debate das ciências sociais na França Caderno CRH: Centro de Recursos Humanos da UFBA Salvador, n.37, p.47-80, 2002.

; GUIMARÃES, N.A.; SUGITA, K. (Org.) Trabalho flexível, empregos precários ? São Paulo: EdUSP, 2009.

LINHART, D. Salariés du privé: une “éthique du dévouement” exigée au nom de l'entreprise. Problèmes politiques et sociaux. La Documentation Française, Paris, n.965, p.32-34, out. 2009.

A desmedida do capital. São Paulo: Boitempo Editorial, 2007.

PASSET, R. A ilusão neoliberal. Rio de Janeiro: Record, 2002.

SEGNINI, L. Relações de gênero nas profissões artísticas: comparac̃ão Brasill- França. In: COSTA, A. O.; SORJ, B.; BRUSCHINI, C.; HIRATA, H. (Org.) Mercado de trabalho e gênero: comparações internacionais. Rio de Janeiro: FGV, 2008. v.1 p.337-354,

SELIGMANN-SILVA, E. Trabalho e desgaste mental: o direito de ser dono de si mesmo. São Paulo: Cortez Editora, 2011.

Os riscos da insensibilidade. In: ARAÚJO, A.; ALBERTO, M. F.; NEVES, M. Y.; ATHAYDE, M. (Org.) Cenários do trabalho. Rio de Janeiro: DP\&A, 2004. p.5172 .

Desemprego e psicopatologia da recessão. In: BORGES, L. H.; MOULIN, M. G. B.; ARAÚJO, M. D. (Org.) Organização do trabalho e saúde: múltiplas relações. Vitória: EDUFES, 2001. p.219-254.

Desgaste mental no trabalho dominado. São Paulo: Cortez, 1994.

SENNETT, R. A corrosão do caráter: consequências pessoais do trabalho no novo capitalismo. São Paulo: Record, 1999.

Record, 2006.

A cultura do novo capitalismo. Rio de Janeiro:

THÉBAUD-MONY, A.; ROBATEL, N. Stress et risques psychosociaux au travail. Problèmes politiques et sociaux. La Documentation Française, Paris, n.965, out. 2009. 
Graça Druck, Tânia Franco

Graça Druck - Doutora em Ciências Sociais, com pós-doutorado na Universidade de Paris XIII. Professora associada I do Departamento de Sociologia e da Pós-Graduação em Ciências Sociais da Universidade Federal da Bahia - PPGCS/FFCH/UFBA. Pesquisadora do Centro de Recursos Humanos/FFCH/UFBA e do CNPq. Realiza pesquisas na área de Sociologia do Trabalho. Autora do livro Terceirização: (Des)Fordizando a Fábrica - um estudo do complexo petroquímico da Bahia (Ed. Boitempo/Edufba, 1999 e 2001) e coorganizadora do livro A perda da razão social do trabalho: precarização e terceirização. (Ed. Boitempo, 2007). Tem artigos publicados em diversos periódicos, Revista Latinoamericana de Estudios del Trabajo -; Pistes; Laboreal; Revista Brasileira de Saúde Ocupacional; Caderno CRH).

Tânia Franco - Doutora em Ciências Sociais pela Universidade Federal da Bahia. Pesquisadora do Centro de Recursos Humanos/FFCH/UFBA no campo temático do trabalho, saúde e meio ambiente. Tem graduação em Economia, Medicina e Mestrado em Ciências Sociais pela UFBA. É organizadora do livro Trabalho, riscos industriais e meio ambiente: rumo ao desenvolvimento sustentável?, (Edufba, 1997) e co-organizadora do livro A perda da razão social do trabalho: precarização e terceirização. (São Paulo: Ed. Boitempo, 2007), com artigos em periódicos diversos (Revista Brasileira de Saúde Ocupacional; Ciência \& Saúde Coletiva; Caderno CRH; RELET - Revista Latinoamericana de Estudios del Trabajo; Pistes; Laboreal). 